\title{
INFLUENCE OF COMPACTED EARTH TOPOGRAPHY ON WATER DROPLET DAMPING
}

\author{
T.Mauffré $^{1}$, F.McGregor ${ }^{1}$, E.Contraires ${ }^{2}$, A.Fabbri ${ }^{1}$ \\ ${ }^{1}$ LTDS, UMR 5513, CNRS, ENTPE, Université de Lyon, 69518 Vaulx-en-Velin \\ France. \\ ${ }^{2}$ LTDS, UMR 5513, CNRS, ECL, Université de Lyon, 69134 Eculy France. \\ E-mails : thibaud.mauffre@entpe.fr, fionn.mcgregor@entpe.fr, elise.contraires@ec- \\ lyon.fr, antonin.fabbri@entpe.fr
}

\begin{abstract}
Raw earth is a granular and porous material very sensitive to water, in particular to rain drops impacting its surface, eroding the construction. The behavior of the droplets impacting the surface remains misunderstood, and surface topography is known to play an important role in wettability, but no consistent procedure to measure it exists today because it is a complex multi-scale material. The aim of this paper is to propose a procedure to measure the height and diameter of the water droplets using an experimental device, and another procedure to measure raw earth surface topography with a dedicated tool. The impact of the earth constitution on surface topography will be soughed, and connections between roughness and droplet behavior will tried to be figured out.
\end{abstract}

Keywords: Raw earth; surface topography; surface absorption; multi-scale roughness; water damping.

\section{INTRODUCTION}

In the current context of global warming, a new interest emerges for the raw earth material, whose carbon impact is very low and its availability huge. In addition, its thermal inertia and its vapor permeability make it an excellent hygrothermal regulator (Fabbri and Morel, 2016). However, this material is sensitive to liquid water, when exposed to rain for example, water can enter the material and then change its mechanical properties. It becomes essential to understand how liquid water behaves on the surface of the earth, and how this behavior can be mastered in order to minimize its impact.

The behavior of liquid water and vapor into volumetric raw earth material has been subject of a lot researches already (Fabbri et al., 2019), (McGregor et al., 2017), yet, the surface absorption for raw earth stills misunderstood. Then, the newness of this approach is to consider surface topography as an influential parameter on the droplet wettability and absorption. As a friable and a non-reflecting material, and furthermore a multi-scale roughness material, a new process to determine surface topography should have been developed for this study. 
J.B.Lee and J.Carmeliet have led very consistent studies on water droplet damping on real porous media (rocks), comparing experimental results to numerical model (Lee et al., 2016a, 2016b, 2016c) even if this work is not focused on surface topography.

Impact of surface topography on water wettability is well-know, as a lot research have been made on surface texturation and multi-scale roughness to make material hydrophobic to super-hydrophobic (Belaud et al., 2014), (Bico, 2002). Though, its influence on water damping droplet remains not totally understood.

\section{MATERIAL AND METHODS}

\subsection{Material}

Three different raw earths, called CRA, STR and ALX, were tested in this study. They all came from existing rammed earth constructions located in Rhône-Alpes region in the South-East of France.

The impact of the proportion of each earth constituent on the raw earth surface topography is researched in this study. The particle size distribution of all three raw earth were determined in accordance with the NF P94-056 norm for particles larger than $80 \mu \mathrm{m}$, and with the NF P94-057 norm for particles smaller than $80 \mu \mathrm{m}$. The summarized results of these two tests are presented in Figure 1.

The adsorption power of the earth has been determined in order to examine the impact of this parameter on the quickness of the water droplet depletion. The adsorption efficiency can be related to the Methylene Blue Value, which is measured on the 0 $80 \mu \mathrm{m}$ fraction of the soil with the NF P94-68 norm. From this value is deduced the activity of the earth. The CRA earth is very active $(a=22)$, STR is moderately active $(\mathrm{a}=10)$, and ALX is little active $(\mathrm{a}=6.7)$. Champiré (2016) has developed more information on the three earths used in this paper, such as the nature of the clays determined by X-rays.

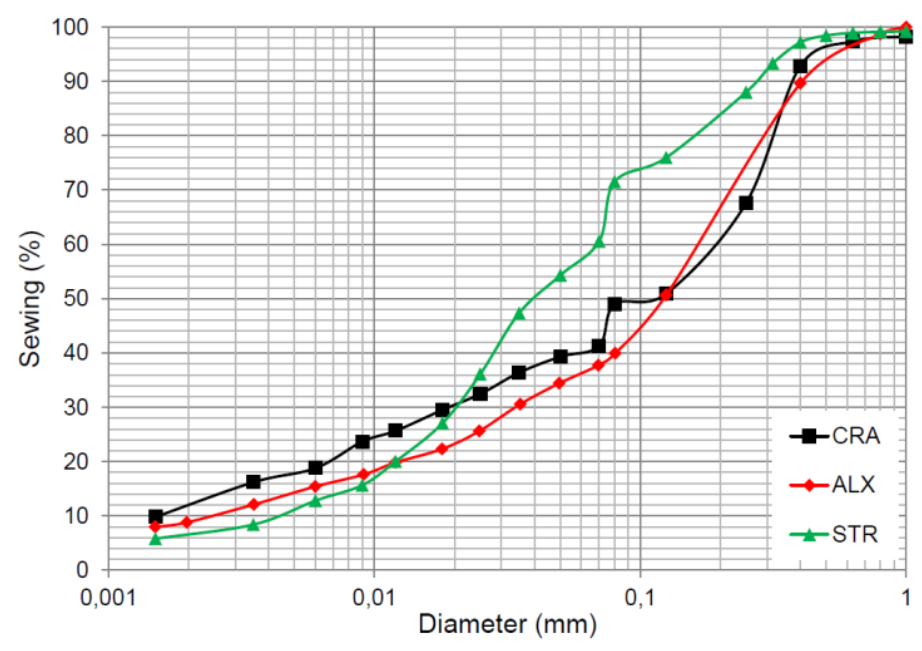

Figure 1 : Particle size distribution of the 3 earths 


\subsection{Sample Preparation}

Compact earth blocks (CEB) are manufactured with the ALTECH Geo50 double compaction manual press. Earth with optimum water content was used to achieve the highest bulk density, with the Proctor test and a procedure described in (Champire et al., 2016). The values are reported in Table 1. After drying, the samples were cored within the CEB's, then dry sawed in slices of $63 \mathrm{~mm}$ diameter and around $10 \mathrm{~mm}$ height. Porosity is determined for all three earths using two tests, pycnometer in order to obtain the volume of the skeleton of the sample, and hydrostatic weighing in order to obtain the total volume of the sample.

Tableau 1 : Characteristics of the compacted earth blocks

\begin{tabular}{|c|c|c|c|}
\hline Earth & Water content $(\%)$ & Bulk density $\left(\mathrm{g} / \mathrm{cm}^{3}\right)$ & Porosity $(\%)$ \\
\hline CRA & 11 & 1.91 & 0.26 \\
\hline STR & 11 & 1.92 & 0.24 \\
\hline ALX & 9 & 1.90 & 0.23 \\
\hline
\end{tabular}

\subsection{Surface Topography}

The surface of the raw earth is very complex to determine. This material is very little reflective, therefore a roughness measurement using an interferometer was not possible. The samples were very friable, so the tactile profilometer measurement wasn't possible either. Moreover, the method used for the sample preparation grants to the surface of the samples some important asperities which were not measurable with an Atomic Force Microscope (AFM). Finally, Scanning Electron Microscopy (SEM) was destructive for our samples.

Because all the classic ways to determine surface topography were unavailing, a first approach was tried with a powerful Optical Microscope KEYENCE. This measurement was able to give a correct surface topography of the core profile of asperities of the surface, but, raw earth is a very complex material with a multi-scale roughness, therefore this method was able to determine the peaks and valley due to the gravels and sands, but not the ones due to silts and smaller particles. With this method, the roughness measured (trough the roughness parameter Arithmetic average height $\mathrm{R}_{\mathrm{a}}$ ) for the CRA samples were around $82 \mu \mathrm{m}$. 2D and 3D views of raw earths CRA and STR, captured with Optical Microscope KEYENCE for a 150x20 zoom, are presented on Figure 2. The CRA sample presents more coarse sands at its surface than the STR sample.

Consequently, a more accurate way to determine surface topography was necessary, it should be capable to detect the multi-scale roughness, and above it all it should be nondestructive for the sample. The STIL SA CHR150-L chromatic confocal sensor was used. The principle of this device is that white light travels through different lens, which then spread the focal length over a discrete number of points over creating a full spectrum of light. On the reflected light, a very precise distance can be measured. The multi-chromatic confocal sensor, has a $1 \mathrm{KHz}$ frequency, which enables the light beam to measure peaks and valleys within a profile of a given length up to 1000 times by second. Then the roughness of the sample can be deduced from this sample with the 
chosen roughness parameters $\left(\mathrm{R}_{\mathrm{a}}, \mathrm{R}_{\mathrm{q}}, \ldots\right)$. By repeating the profile measurement several times with an offset of a few micrometers (between 0 to 5), a map of peaks and valleys of the sample surface can be drawn, therefore surface roughness parameters can be deduced $\left(\mathrm{S}_{\mathrm{a}}, \mathrm{S}_{\mathrm{q}} \ldots\right)$. The software that was used to convert automatically the .csv data into roughness parameters was MOUNTAINS V2.

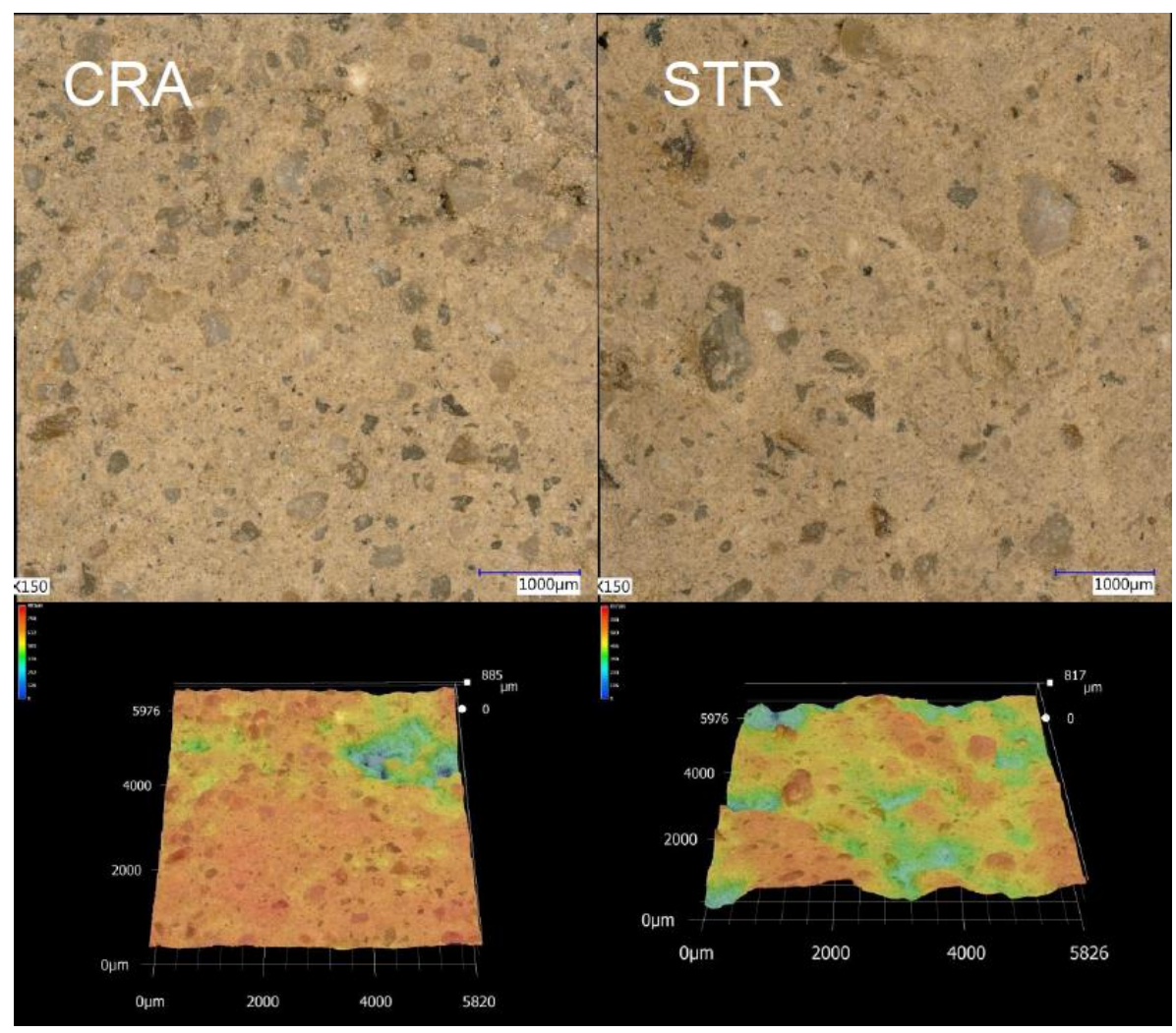

Figure 2: 2D and 3D view of CRA and STR earths with KEYENCE optical microscope (lens: 150x20)

Although surface roughness parameters are the most commonly used to describe surface topography in the literature, the choice has been made to work with profile roughness parameters, because it was the only way to distinguish several scale of roughness. As shown in Figure 3, a classical $0.8 \mathrm{~mm}$ Gaussian filter was applied to the raw profile (in blue), called primary profile and noted $\mathrm{P}_{\mathrm{a}}$. Two new profiles can so be separated: Wavering profile in red, noted $\mathrm{W}_{\mathrm{a}}$, and Roughness profile in green, noted $R_{a}$. Sum of both profile $W_{a}+R_{a}$ equals to the Primary profile $P_{a}$. While the average $R_{a}$ measured with the optical microscope for the CRA sample was around $82 \mu \mathrm{m}$, the new measure with the multi-chromatic confocal sensor can give three values: $\mathrm{P}_{\mathrm{a}}=92 \mu \mathrm{m}$; $\mathrm{W}_{\mathrm{a}}=84.7 \mu \mathrm{m} ; \mathrm{R}_{\mathrm{a}}=24.5 \mu \mathrm{m}$. Primary profile $\mathrm{P}_{\mathrm{a}}$ and roughness profile $\mathrm{R}_{\mathrm{a}}$ measured by optical microscope are close, which guaranties the coherency of the measurement of the main peaks and valleys, however the multi-chromatic confocal sensor gives a lot more information thanks to his great resolution capacity. This distinction between the two profiles was not possible with surface parameters. 


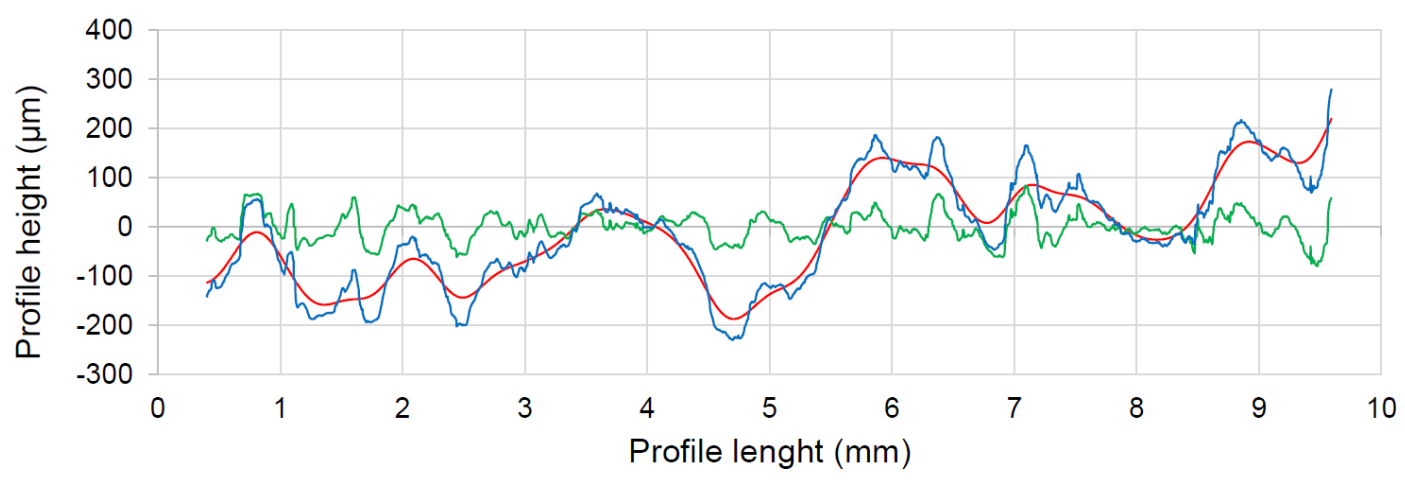

Figure 3: $0.8 \mathrm{~mm}$ Gaussian filter applied to the primary profile of a CRA sample

A consistent protocol for accurate measures of theses roughness parameters has been sought in this study. The standard deviation was acceptable for five profile measurements made randomly at the surface of the sample, as shown in Figure 4. Mostly on the $\mathrm{W}_{\text {a }}$ parameter, the main problem of the repeatability of the measures was the impact of the randomness. Indeed, the presence of a valley caused by the manipulation of the sample and due to the sample friability could change considerably the results. All the values for roughness parameters of the three earths are reported in Table 2.

Table 2: Roughness parameters results with chromatic confocal sensor

\begin{tabular}{|c|c|c|c|c|c|c|c|c|c|c|c|}
\hline Earth & \multicolumn{4}{|c|}{ STR } & \multicolumn{4}{c|}{ CRA } & \multicolumn{3}{c|}{ ALX } \\
\hline Sample & 1 & 2 & 3 & 4 & 5 & 6 & 7 & 8 & 9 & 10 & 11 \\
\hline $\mathrm{Pa}(\mu \mathrm{m})$ & 52,3 & 62,6 & 74,8 & 89,9 & 80,8 & 87,2 & 83,3 & 82,0 & 105,0 & 95,0 & 104,0 \\
\hline $\mathrm{Ra}(\mu \mathrm{m})$ & 15,8 & 15,8 & 17,4 & 17,8 & 23,5 & 24,6 & 21,7 & 23,2 & 19,5 & 19,4 & 20,8 \\
\hline $\mathrm{Wa}(\mu \mathrm{m})$ & 45,4 & 57,6 & 76,4 & 81,0 & 77,9 & 70,6 & 76,4 & 72,1 & 94,4 & 85,0 & 96,0 \\
\hline
\end{tabular}

The average values of $\mathrm{R}_{\mathrm{a}}$ and $\mathrm{W}_{\mathrm{a}}$ parameter for STR, CRA and ALX earth samples are respectively $16.7 \mu \mathrm{m}, 23.2 \mu \mathrm{m}, 19.9 \mu \mathrm{m}$, and $61.7 \mu \mathrm{m}, 74.2 \mu \mathrm{m}, 91.8 \mu \mathrm{m}$. These average values can clearly distinguish three different surface topographies. The average value of the standard deviation on the five measures of each sample for $R_{a}$ and $\mathrm{W}_{\mathrm{a}}$ parameters are respectively $3.8 \mu \mathrm{m}$ and $19.2 \mu \mathrm{m}$.

These results may be explained by linking with granular distribution in Figure 1. At the sight of the results, $\mathrm{R}_{\mathrm{a}}$ and $\mathrm{W}_{\mathrm{a}}$ seems to be independent. Then our hypothesis is that $R_{a}$ depends of the amount of small components such as clays or silts, while the $W_{a}$ depends mostly of coarse sands. STR earth presents a smaller $\mathrm{W}_{\mathrm{a}}$ because it contains few coarse sands compared to CRA and ALX, and its $R_{a}$ is also smaller because it 
contains less clays than the others. However, we must keep in mind that nature of the components and the sawing process may affect the results.

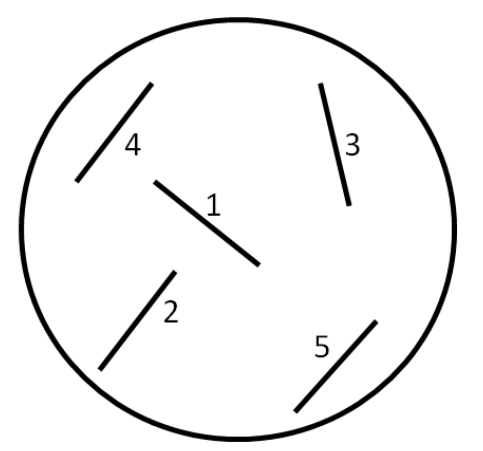

Figure 4 : Measurement protocol

\subsection{Water Damping Experimental Device}

The water droplet damping test was performed with an experimental device composed by the various elements presented on figure 5 . The sample (1) was laid on the frame, and movable in $X, Y, Z(2,3,4)$. Above the sample, was placed the syringe (5) connected to an electronic syringe pump, governed by the KRUSS software on the computer (8). Behind the sample, was a lamp (6), and in front of the sample were a AMETECH MIRO M130 camera (7), inclined by a 5 degrees angle compared to the plan where the sample laid. To acquire the images, the software PHANTOM CC2.1 was used.

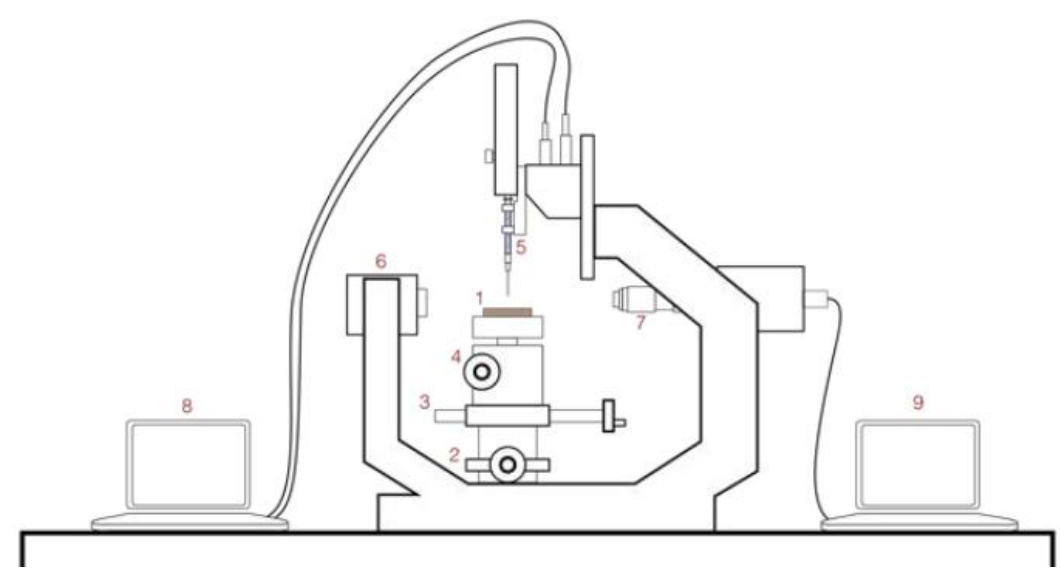

Figure 5: Water damping recording experimental device

For the experiments, droplets of $9 \mu \mathrm{l}$ were created by the syringe pump, to get rid of gravity effects. The water droplet velocity was $1 \mathrm{~m} / \mathrm{s}$. The highest frequency of the PHANTOM camera (3000 fps) was used to capture the videos, because the absorption of the water by the raw earth was very quick (around $4 \mathrm{~ms}$ ).

A custom-made MATLAB code was used for determination of the height of the droplet $\mathrm{h}(\mathrm{t})$. Contrariwise, this code was unable to measure the dynamic contact angle because 
of the opacity of the earth, which makes the droplet difficult to distinguish from the surface. The spreading diameter $\mathrm{D}(\mathrm{t})$ of the impacting droplet was followed by IMAGE-J software, at the contact line between substrate and droplet, as shown on Figure 6. One pixel represents $15.5 \mu \mathrm{m}$ on the picture, and the measurement precision is around 10 pixels at both edge of the droplet. The maximum margin of error on the spreading diameter $\mathrm{D}(\mathrm{t})$ is $1 \%$.

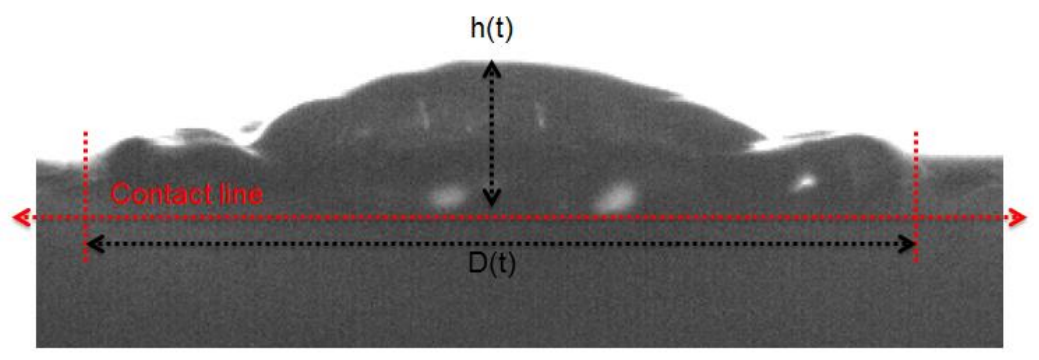

Figure 6: Parameters measured on the droplet

\section{RESULTS}

\subsection{Droplet Height Compared to Time}

The results of the drop highest point compared to time, for two earth samples where the droplet had a very different behavior, are reported on Figure 7. The droplet have been impacting the sample on its edges, in order to facilitate $h(t)$ and $D(t)$ measurement, as presented on Figure 8.

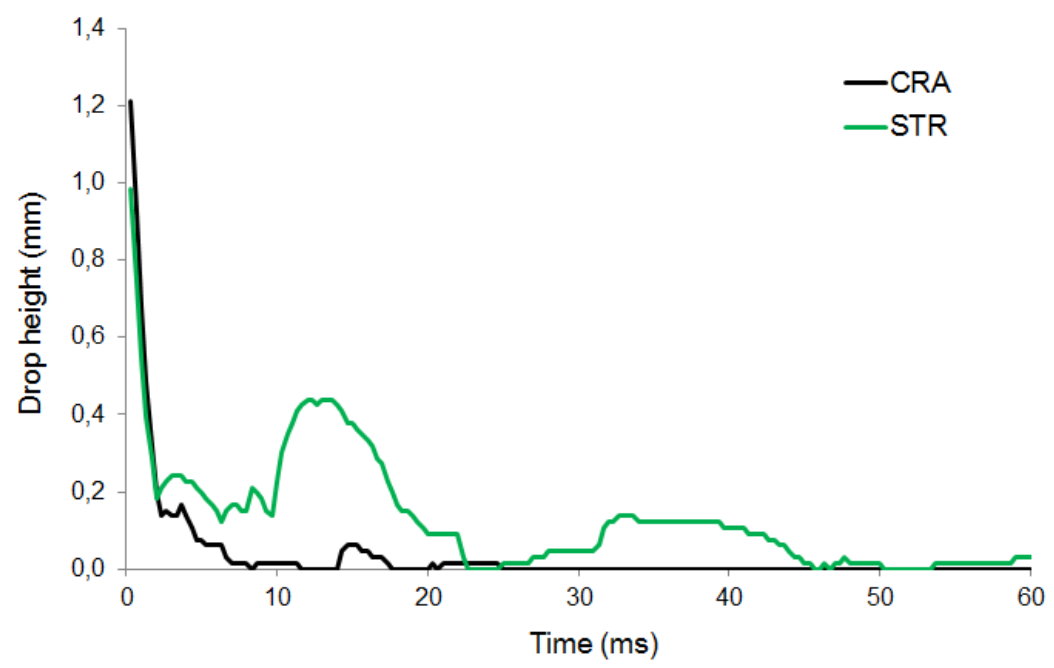

Figure 7: Droplet maximal height $\mathrm{h}(\mathrm{t})$ compared to time for STR and CRA samples 
For the STR sample, the behavior of the droplet on the earth surface can be divided into four major steps: (1) the droplet enters in contact with the sample surface, and then with the kinetic energy stored during the fall, the droplet starts to spread until it reaches its maximum spreading (2). Then, the droplet bounces once to reach a new high peak (3), before bouncing a little and being fully absorbed by the earth (4). The behavior of the droplet on this sample is called oscillating. All this session is really quick, indeed it last only $50 \mathrm{~ms}$ before being fully absorbed. However it is even quicker for the CRA sample, where the droplet is not bouncing but absorbed after maximum spreading. The drop is fully absorbed around $20 \mathrm{~ms}$. This behavior is called cushioned.

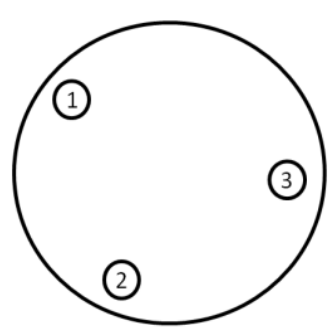

Figure 8: Position of the impacting droplets for $h(t)$ measurement for one sample

\subsection{Droplet Radius Compared to Time}

The diameter of the droplet, from the beginning of the impact until it reaches its maximum size $D_{\max }$, has been measured from the images captured by the camera. For the three samples, the droplet speed during the fall was $1 \mathrm{~m} / \mathrm{s}$.

For all three samples, during the first two milliseconds, $D(t)$ increase quickly up to $1.85 \mathrm{~m} / \mathrm{s}$. They all start stagnating around $4 \mathrm{~ms}$. D(t) remains constant after its maximum spreading, and will start depleting in keeping this diameter constant, without receding. Knowing the earth is a porous material, and based on (Lee et al., 2016a), this phenomenon can be explained by the fact that the droplet is pinned to the surface by the capillary forces from the porous media, when they become strong enough to break the air layer between the droplet and the surface.

\section{DISCUSSION}

In this part, we have been trying to figure out the connections between the difference of behavior of the droplet observed on the camera, and the roughness parameters measured thanks to the multi-confocal sensor. For all the samples, $D_{\max }$ has been plotted in function of $R_{a}$. The results are presented on Figure 9. 


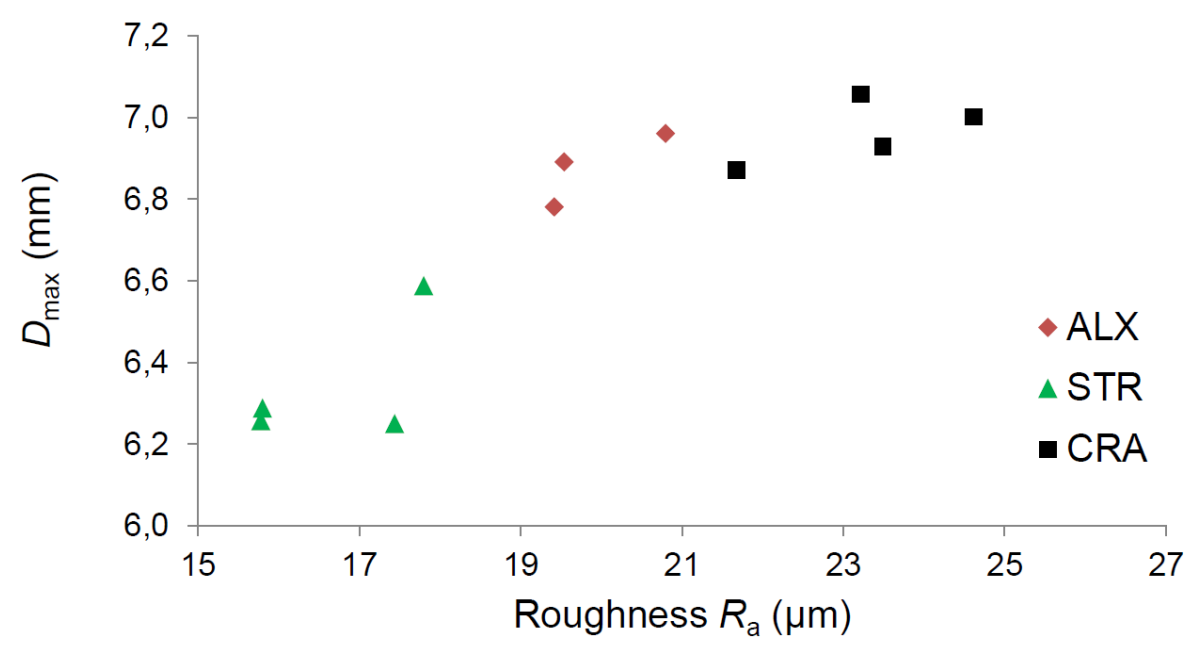

Figure 9: $D_{\max }$ vs $R_{a}$ for the entire sample tested

There is a clear tendency between $\mathrm{D}_{\max }$ and $\mathrm{R}_{\mathrm{a}}$. The higher $\mathrm{R}_{\mathrm{a}}$ is, the more the droplet will spread. Assuming that an air layer is present under the droplet while it spreads, as postulated by (Lee et al., 2016a), this connection can be explained by the ratio of air of this air/earth composite surface. The ratio of air will rise with the increase of $R_{a}$, because the difference between peaks and valley is higher. It can be supposed that the less the droplet is in contact with the earth, the less the capillary forces will take place and pin the droplet, stopping its spreading. Finally, $h(t)$ is small while $D_{\max }$ is great, it can be understood as the more the droplet is in contact with the earth, the quicker the droplet will be absorbed, because of the capillary forces and great earth absorption.

\section{CONCLUSION}

After the elimination of all classical technique to measure the raw earth surface, a new technique has been performed on three different raw earths, with a chromatic confocal sensor, allowing the distinction between two scale of roughness $\mathrm{W}_{\mathrm{a}}$ and $\mathrm{R}_{\mathrm{a}}$. The granular distribution has put in light the impact of the amount of different constituents on theses parameters.

An experimental water droplet damping system has led us to an original work on raw earth surfaces. Spreading diameter $D(t)$ and droplet maximal height $h(t)$ were followed thanks to software, in order to observe the behavior of the impacting droplet on different raw earth surface.

The behavior of a droplet can vary from oscillating to cushioned, playing considerably on the absorption time. The droplet is pinned to the surface after its maximum spreading $D_{\max }$ when the capillary forces become strong enough to break the air layer under the droplet. 
Finally, wettability and roughness parameters have been linked to show that $D_{\max }$ scale with $\mathrm{R}_{\mathrm{a}}$. The maximum spreading will increase with the roughness of the raw earth surface, causing a quicker depletion of the droplet.

It has been shown that the raw earth composition can influence the raw earth surface topography and the water droplet wettability at its surface. However, the influence of some parameters such as porosity, droplet velocity, liquid viscosity,... has not been tested in this study and must be examined in further work. Moreover, a comparison with numerical models already developed for porous media may be interesting for the future.

\section{REFERENCES}

A. Fabbri, J.-C. Morel. Chapter 10: Earthen Materials and Constructions in Nonconventional and Vernacular Construction Materials, Kent A. Harries, B. Sharma ed., Woodhead Publishing; 2016

A. Fabbri, L. Soudani, F. McGregor, J-C. Morel. Analysis of the water absorption test to assess the intrinsic permeability of earthen materials, Construction and Building Materials 199:154-162, 2019

F. McGregor, A. Fabbri, J. Ferreira, T. Simoes, P. Faria, and J.-C. Morel. Procedure to determine the impact of the surface resistance on the hygric properties of composite clay plasters. Materials and Structures 50(4), 2017.

J. B. Lee, D. Derome, and J. Carmeliet. Drop impact on natural porous stones. Journal of Colloid and Interface Science, 469:147-156, $2016 \mathrm{a}$.

J B Lee, A I Radu, P Vontobel, D Derome, and J Carmeliet. Absorption of impinging water droplet in porous stones. Journal of Colloid and Interface Science, 471:59-70, $2016 b$.

J. B. Lee, D. Derome, A. Dolatabadi, and J. Carmeliet. Energy Budget of Liquid Drop Impact at Maximum Spreading: Numerical Simulations and Experiments. Langmuir, 32:1279-1288, 2016c.

V Belaud, S Valette, G Stremsdoerfer, M Bigerelle, and S Benayoun. Tribology International Wettability versus roughness: Multi-scales approach. Tribology International, 1-7, 2014.

J. Bico, U. Thiele, and D. Quéré. Wetting of textured surfaces. Colloids and Surfaces A: Physicochemical and Engineering Aspects, 206(1-3):41-46, 2002. 
F. Champiré, A. Fabbri, J.-C. Morel, H. Wong, and F. McGregor. Impact of relative humidity on the mechanical behavior of compacted earth as a building material. Construction and Building Materials, 110:70-78, 2016. 